TECHNICAL TRANSACTIONS 7/2019

CIVIL ENGINEERING

DOI: $10.4467 / 2353737$ XCT.19.076.10727

SUBMISSION OF THE FINAL VERSION: 29/05/2019

\author{
Yasushi Uematsu (iD) orcid.org/0000-0002-9186-7835 \\ yasushi.uematsu.d8@tohoku.ac.jp \\ Department of Architecture and Building Science, Tohoku University, Japan
}

Roma Yamamura (iD) orcid.org/0000-0002-6282-4596

r.yamamura0623@gmail.com

Central Japan Railway Company (formerly Graduate Student, Graduate School of

Engineering, Tohoku University)

\title{
WIND LOADS FOR DESIGNING THE MAIN WIND-FORCE RESISTING SYSTEMS OF CYLINDRICAL FREE-STANDING CANOPY ROOFS
}

\author{
OBCIĄŻENIA WIATREM PRZY PROJEKTOWANIU GEÓWNYCH \\ SYSTEMÓW ODPORNYCH NA SIŁĘ WIATRU CYLINDRYCZNYCH DACHÓW \\ WOLNOSTOJĄCYCH
}

\begin{abstract}
Wind loads on cylindrical free-standing canopy roofs were investigated in a wind tunnel. First, the overall aerodynamic forces and moments were measured using a force balance. The distributions of net wind pressures provided by the difference between wind pressures on the top and bottom surfaces of the roof were then measured along two representative arc lines. Based on the results, the net wind-pressure coefficients for designing such roofs are proposed as a function of the rise-to-span ratio for two representative wind directions: one perpendicular to the eaves, the other inclined at an angle of $45^{\circ}$ to the eaves. The roof is divided into three zones and constant net wind-pressure coefficients are specified for these zones. Two load cases providing the maximum tension and compression in the columns supporting the roof are considered as the most important load effect for discussing the design wind loads.

Keywords: cylindrical free-standing canopy roof, wind load, main wind-force resisting system, wind tunnel experiment, dynamic load effect
\end{abstract}

\section{Streszczenie}

Obciążenia wiatrem na cylindrycznych dachach wolnostojących zadaszenia zbadano w tunelu aerodynamicznym. Ogólne sily i momenty aerodynamiczne zmierzono za pomocą równowagi sit. Następnie zmierzono rozkłady ciśnień wiatru netto, które wynikają z różnicy ciśnień wiatru na górnej i dolnej powierzchni dachu, wzdłuż dwóch reprezentatywnych linii łuku. Na podstawie wyników zaproponowano współczynniki ciśnienia wiatru netto do projektowania takich dachówjako funkcję stosunku wzrostu do rozpiętości dla dwóch reprezentatywnych kierunków wiatru: jednego prostopadłego do okapu, drugiego nachylonego pod kątem $45^{\circ}$ do okap. Dach podzielony jest na trzy strefy i dla tych stref określono stałe współczynniki ciśnienia wiatru netto. Dwa przypadki obciążeń zapewniające maksymalne naprężenie i ściskanie kolumn podtrzymujących dach są uważane za najważniejszy efekt obciążenia do omawiania obliczeniowych obciążeń wiatrem.

Słowa kluczowe: cylindryczny dach wolnostojący, obciążenie wiatrem, główny system oporu wiatru, eksperyment w tunelu aerodynamicznym, efekt obciążenia dynamicznego 


\section{Introduction}

Free-standing canopy roofs are widely used for structures providing shade and weather protection in public spaces. The roofs are usually supported by columns and no walls. Because both sides of the roof are exposed to the flow, the wind forces acting upon the roof are more complicated than those acting upon enclosed structures. Furthermore, being light and flexible, the roofs are vulnerable to dynamic wind actions. Therefore, wind resistance is one of the most important technological problems when designing these roofs.

Although a large database of knowledge exists on wind-pressure distributions on enclosed structures of various shapes (e.g., Architectural Institute of Japan, 2015 [1]), only a few studies have been conducted on wind loading on free-standing canopy roofs. This may be due to difficulties in making models and measuring wind-pressure distributions in wind tunnel experiments. Many pressure taps are required to be installed on both the top and bottom surfaces of the roof in order to measure the distribution of net wind pressures in detail. In practice, however, the number of pressure taps is limited because the roof thickness should be as small as possible, considering the practical situation.

Regarding planar free-standing canopy roofs, such as gable and mono-sloped roofs, extensive research has been performed by several researchers, e.g., Gumley [3], Letchford and Ginger [4], Ginger and Letchford [2], Natalini et al. [6] and Uematsu et al. [10-12]. Indeed, the net wind-pressure coefficients for designing such roofs are specified in building codes and standards (e.g., Architectural Institute of Japan [1]). By comparison, only a few studies have been performed on the wind loading of curved free-standing canopy roofs. The Australian/New Zealand standard specifies the net wind-pressure coefficients for HP-shaped free-standing canopy roofs, although the range of roof geometry is rather limited. Wind loads on HP-shaped free-standing canopy roofs were studied experimentally by Uematsu et al. [13, 14] and numerically by Takeda et al. [8] for a wide range of roof geometry. Natalini et al. [7] investigated the wind loads on cylindrical free-standing canopy roofs in a wind tunnel. They measured only the mean wind pressures acting on the roof. The dynamic load effect of turbulent winds was not discussed.

The present paper investigates the design wind loads for the main wind-force resisting systems of cylindrical free-standing canopy roofs, based on measurements of the overall aerodynamic forces and moments on the roof model as well as of the distributions of the net wind-pressure coefficient along two representative arc lines on the roof. The wind tunnel models were made using a $3 \mathrm{D}$ printer, which made the model thickness as thin as $1 \mathrm{~mm}$ for the overall wind-force measurements and $2 \mathrm{~mm}$ for the wind-pressure measurements.

\section{Experimental apparatus and procedure}

Figure 1 shows the model structure under consideration together with the notation and coordinate system used in the present paper. The span $B$ and the width $W$ were both $15 \mathrm{~m}$. The mean roof height $H$ was fixed at $8 \mathrm{~m}$ regardless of the rise-to-span ratio $f / B$. Therefore, 
the ridge height $h$ depended on $f / B$, ranging from $8.8 \mathrm{~m}$ to $11.8 \mathrm{~m}$. The wind tunnel models were made using a $3 \mathrm{D}$ printer with a geometric scale of $\lambda_{\mathrm{L}}=1 / 100$. Two series of wind tunnel experiments were performed. In the first series of experiments, the lift $L$ and the aerodynamic moments, $M_{\mathrm{x}}$ and $M_{y}$, about the $x$ and $y$ axes were measured using a six-component force balance, changing the $f / B$ ratio from 0.1 to 0.5 . In the second series of experiments, the net wind-pressure distributions along two representative arc lines, referred to as lines $\mathrm{C}$ and $\mathrm{E}$ in the present paper (see Fig. 2a), were measured by using differential pressure transducers, changing the $f / B$ ratio from 0.1 to 0.4 . The roof thickness and the diameter of four columns supporting the roof were respectively $1 \mathrm{~mm}$ and $5 \mathrm{~mm}$ in the first series of experiments, and $2 \mathrm{~mm}$ and $6.5 \mathrm{~mm}$ in the second series of experiments. Figure $2 \mathrm{~b}$ shows the wind tunnel models with $f / B=0.2$ and 0.4 used in the second series of experiments.

The wind tunnel flow was a turbulent boundary layer simulating natural winds over typical suburban terrain. The power law exponent of the mean wind speed profile was approximately 0.22 . The design wind speed $U_{\mathrm{H}}$ at the mean roof height $H$ was determined based on the AIJ Recommendations for Loads on Buildings (2015) [1], assuming that the 'basic wind speed' $U_{0}$ is $35 \mathrm{~m} / \mathrm{s}$ and the terrain category is III, which corresponds to suburban terrain. In practice, the value of $U_{\mathrm{H}}$ was calculated as $27.8 \mathrm{~m} / \mathrm{s}$. In the wind tunnel experiment, the wind speed $U_{H}$ was $9 \mathrm{~m} / \mathrm{s}$ for $f / B \leq 0.2$ and $10 \mathrm{~m} / \mathrm{s}$ for $f / B \geq 0.3$, except in Section 3.1, where the effect of the Reynolds number on the wind-pressure distribution is investigated. The velocity scale $\lambda_{\mathrm{V}}$ and the time scale $\lambda_{\mathrm{T}}$ of the wind tunnel experiments were calculated respectively as $1 / 3.0$ and $1 / 32.4$ for $f / B \leq 0.2$ and $1 / 2.8$ and $1 / 36.0$ for $f / B \geq 0.3$. The turbulence intensity $I_{\mathrm{uH}}$ of the wind tunnel flow at the mean roof height $H$ was approximately 0.16 . The wind direction $\theta$ was changed from $0^{\circ}$ to $90^{\circ}$ with an increment of $5^{\circ}$, considering the symmetry of the model (see Fig. 1).

The sampling rate of measurements was $200 \mathrm{~Hz}$ in the first series of experiments and $500 \mathrm{~Hz}$ in the second series of experiments. In the second series of experiments (pressure measurements), the wind pressures at all pressure taps were measured simultaneously. The tubing effect on the measured fluctuating wind pressures was compensated for in the frequency domain by using the frequency response function of the measuring system used in the experiment. Each measurement was performed for a duration of 10 minutes at full scale. The measurements were repeated 10 times under the same condition. The statistical values of wind-pressure coefficients etc. were evaluated by applying ensemble average to the results of these consecutive 10 runs.

\section{Experimental results}

\subsection{Effect of the Reynolds number on the wind-pressure distribution on the roof}

It is well accepted that the wind pressures on curved structures are affected by the Reynolds number $R e$. This is because the location of flow separation from the structure's surface depends on $R e$. Therefore, in this section, the effect of Re on the wind-pressure distribution on the roof is 
first investigated by changing the wind speed $U_{\mathrm{H}}$. The Reynolds number is defined in terms of $U_{\mathrm{H}}$ and twice the radius of the curvature $(R)$ of the cylindrical roof in the $(x, z)$-plane in order to relate the flow around the circular free-standing canopy roof with the flow around a circular cylinder, in which the diameter (= twice the radius) of the cylinder is usually used for defining Re.

In the experiment of this section, the wind speed $U_{\mathrm{H}}$ is varied from 3 to $11 \mathrm{~m} / \mathrm{s}$; the corresponding Reynolds numbers range from $0.33 \times 10^{5}$ to $3.09 \times 10^{5}$. Figures 3 and 4 respectively show the distributions of the mean values of wind-pressure coefficients, $C_{\mathrm{pt}}$ and $C_{\mathrm{pb}}$, on the top and bottom surfaces and the net wind-pressure coefficient $C_{\mathrm{f}}$ along the centreline (line $C$ ) for $f / B=0.1$ and 0.4 , which are obtained at various Reynolds numbers. The wind direction is $\theta=0^{\circ}$. The wind-pressure coefficients are defined in terms of the velocity pressure $q_{\mathrm{H}}\left(=1 / 2 \rho U_{\mathrm{H}}{ }^{2}\right.$, with $\rho$ being the air density) at the mean roof height $H$ of the wind tunnel flow. The net wind-pressure coefficient $C_{\mathrm{f}}$ is defined as $C_{\mathrm{f}}=C_{\mathrm{pt}}-C_{\mathrm{pb}}$. In the figure, ' $s$ ' represents the coordinate along the arc line with the origin at the windward edge, normalised by the maximum value $s_{\max }$.

When $f / B=0.1$ (see Fig. 3), the mean $C_{p t}$ distribution does not change with $R e$, which implies that the wind flows along the roof's top surface without separation. By contrast, when $f / B \geq 0.2$, the mean $C_{p t}$ distribution changes with Re. This feature indicates that the flow separates from the roof's top surface at some point and the separation point shifts with Re. When $f / B=0.2$, the separation point is close to the trailing edge of the roof; the results are not shown here in order to save space. As the $f / B$ ratio increases, the separation point shifts windward. Figure 4 shows the results for $f / B=0.4$. It is found that the mean $C_{\mathrm{pt}}$ distributon is hardly affected by $R e$ when $R e>1.0 \times 10^{5}$. This feature is consistent with the finding by Macdonald et al. [5] for cylindrical structures. They investigated the Reynolds number effect on the flow around circular cylinders by comparing the wind tunnel results obtained at various Reynolds numbers with the results of full-scale measurements on actual silos. According to their results, the wind-tunnel results obtained at $R e>1.0 \times 10^{5}$ in a turbulent boundary layer may reasonably represent the practical full-scale situation.

The flow separates downward at the windward edge of the roof in any case of $f / B$. However, the mean $C_{\mathrm{pb}}$ distribution on the bottom surface is hardly affected by $R$. Therefore, the change in the net wind-pressure coefficient distribution is mainly attributed to the $C_{\mathrm{pt}}$ distribution. In conclusion, the measurements are made at $R e>1.0 \times 10^{5}$ in the following sections; in practice, $U_{\mathrm{H}}=9 \mathrm{~m} / \mathrm{s}$ or $10 \mathrm{~m} / \mathrm{s}$.

\subsection{Comparison with the previous experimental results}

Natalini et al. [7] measured the distributions of mean wind-pressure coefficients on the top and bottom surfaces of cylindrical free-standing canopy roofs. The geometry of their models was as follows: $B=15 \mathrm{~cm}, W=30 \mathrm{~cm}$ or $60 \mathrm{~cm}(W / B=1$ or 2$), f=3 \mathrm{~cm}(f / B=0.2)$, $h=5-9 \mathrm{~cm}$, and the roof thickness was $2 \mathrm{~mm}$. The wind tunnel flow was a turbulent boundary layer with a power law exponent of 0.24 . The test condition is similar to that of the present study.

Figures 5 and 6 show the distributions of mean wind-pressure coefficients along lines $\mathrm{E}$ and $\mathrm{C}$ when $\theta=0^{\circ}$ and $30^{\circ}$, respectively; the $f / B$ ratio was 0.2 . The results were compared with those 
of Natalini et al. [7] for $W=30 \mathrm{~cm}$ and $h=6 \mathrm{~cm}$. It was found that both results agree relatively well with each other for the distributions along the centreline. Regarding the distributions along the edge line (line $\mathrm{E}$ in the present experiment), the agreement is somewhat poor, paticularly when $\theta=30^{\circ}$, although both results follow similar trends. This difference may be due to the difference in the distance between the line of pressure taps and the verge of the roof; it was $2.5 \mathrm{~mm}$ in the present experiment, while it was $5 \mathrm{~mm}$ in Natalini et al's experiment. The pressure distribution near the verge seems to be sensitive to the 3-dimensional effect of the flow.

Next, the present results for the mean wind-pressure coefficients on the top surface were compared with those on the enclosed buildings with circular roofs obtained in a previous study. Figure 7 shows a comparison between the present results for $f / B=0.1$ and 0.4 and those of Ueda et al. [9] for enclosed buildings with $f / B=0.1$ and 0.5 when $\theta=0^{\circ}$. The geometry of Ueda et al.'s model was as follows: $B=25 \mathrm{~cm}, W=50 \mathrm{~cm}(W / B=2)$, and the eave height is $5 \mathrm{~cm}$. The value of $I_{\mathrm{uH}}$ of their wind tunnel flow was approximately 0.2 , which is somewhat larger than that of the present experiment.

When the $f / B$ ratio is relatively large, the distributions on a free-standing canopy roof and enclosed building look similar to each other. The location of flow separation is almost the same. By comparison, when $f / B=0.1$, the distributions are quite different from each other, particularly in the windward area $\left(s / s_{\max }<0.5\right)$. In the case of an enclosed building, the flow separates upward at the leading edge of the roof and then re-atchhes on the roof, generating large levels of suction near the leading edge. By contrast, in the case of a free-standing canopy roof, the flow does not separate at the leading edge and the windward area is subjected to positive (downward) wind pressures. It is thought that these flow patterns are quite different from each other. Generally speaking, it seems difficult to estimate the net wind-pressure coefficient distribution on free-standing canopy roofs from the wind-pressure distributions on the corresponding enclosed buildings, particularly for smaller values of $f / B$.

\subsection{Mean wind-pressure distributions}

Figure 8 shows the effects of $f / B$ on the distributions of mean wind-pressure coefficients and mean net wind-pressure coefficients along line $C$ when $\theta=0^{\circ}$. In the case of $f / B \geq 0.2$, the distribution on the top surface (a) has an inflection point, the location of which roughly corresponds to the flow separation point. As the $f / B$ ratio increases, the location shifts windward and both the maximum and minimum pressure coefficients increase in magnitude. The distribution on the bottom surface (b) significantly changes with $f / B$. The flow separates downward at the leading edge of the roof. When $f / B=0.1$, the separated flow soon re-attaches on the bottom surface of the roof and the pressure gradient is large in the separation bubble zone. By contrast, when $f / B \geq 0.3$, the bottom surface is entirely within the separation bubble and subjected to large suctions. The mean net wind pressure resulting from the difference between the mean wind pressures on the top and bottom surfaces is positive in the windward area (e.g., $s / s_{\max }<0.2$ ) while it is nearly constant in the leeward area (e.g., $s / s_{\max }>0.8$ ).

Figure 9 shows the distributions of mean wind-pressure coefficients and mean net windpressure coefficients along line $\mathrm{E}$ when $\theta=30^{\circ}$. It is found that the area of $0.5<s / s_{\max }<0.8$ on 
the top surface is subjected to high levels of suction when $f / B \geq 0.2$. This phenomenon may be due to a conical vortex generated along the leeward verge. However, the area of such high suction is thought to be limited, according to the results of Natalini et al. [7].

\subsection{Aerodynamic force and moment coefficients}

With regard to the aerodynamic force and moment coefficients, the lift coefficient $C_{\mathrm{L}}$ and the aerodynamic moment coefficient $C_{\mathrm{My}}$ defined by Eqs. (1) and (2), are important for evaluating the design wind-force coefficients (see Uematsu et al. [11, 13]).

$$
C_{\mathrm{L}}=\frac{L}{q_{\mathrm{H}} \cdot B \cdot W} \quad C_{\mathrm{My}}=\frac{M_{\mathrm{y}}}{q_{\mathrm{H}} \cdot R \cdot f \cdot W}
$$

Figure 10 shows the variation of mean $C L$ and $C M y$ values with wind direction $\theta$. Both values become the maximum at $\theta \approx 0^{\circ}$ when $f / B=0.1$. However, they become the maximum at an oblique wind direction when $f / B \geq 0.2$. The wind directions providing the maximum $C_{\mathrm{L}}$ and $C_{\mathrm{My}}$ values increase with an increase in $f / B$.

The local (sectional) values of $C_{\mathrm{L}}$ and $C_{\mathrm{My}}$ are calculated from the $C_{\mathrm{f}}$ distribution along line $\mathrm{C}$. When the wind pressures are perfectly correlated with each other in the $y$ direction, the local value coincides with that for the overall roof. The results for the mean $C_{\mathrm{L}}$ and $C_{\mathrm{My}}$ values (local values) are plotted in Figure 11 together with those obtained from the overall wind-force measurements by using a force balance. The open and closed symbols represent the results of overall wind-force measurements and those predicted from the wind-pressure distributions along line $C$, respectively. When $\theta=0^{\circ}$ and $90^{\circ}$, both results agree well with each other. This is because the variation of wind-pressure coefficients in the $y$ direction is relatively small for these wind directions. In the case of oblique winds, the difference becomes larger as the $f / B$ ratio increases, although both results follow similar trends. The local values are generally larger in magnitude than those for the overall roof. This feature implies that we can evaluate the net wind-pressure coefficients for designing the cylindrical free-standing canopy roofs based on the wind-pressure distributions along line $\mathrm{C}$, which may provide somewhat conservative estimations of the design wind loads.

\subsection{Load effects}

In this section, focus is on the axial forces induced in the columns as the most important load effect for discussing the design wind loads for the main wind-force resisting systems, assuming that the roof is rigid and supported by four corner columns in the same manner as in our previous studies (Uematsu et al. $[11,13]$ ). Uematsu et al. $[15,16]$ investigated the application of the proposed net wind-pressure coefficients for planar free-standing canopy roofs. They examined whether the proposed net wind-pressure coefficients based on the axial forces can evaluate the other load effects appropriately and whether they can be applied to the other structural systems, such as a cantilever type. They computed the bending moments and shear forces in the columns using the proposed net wind-pressure coefficients and compared the results with the maximum 
values of the bending moments and shear forces obtained from the time history analyses of these load effects, in which the time history of wind-pressure coefficients at many points on the roof was used. It was found that the proposed net wind-pressure coefficients could provide appropriate estimation of the bending moments and shear forces.

The axial forces $N$ were computed using the time history of $C_{\mathrm{L}}, C_{\mathrm{Mx}}$ and $C_{\mathrm{My}}$ and then nondimensionalised by $1 / 4 q_{\mathrm{H}} B W$. Figure 12 shows the variation of the maximum and minimum peak values, $N_{\text {max }}^{*}$ and $N_{\text {min }}^{*}$ of the non-dimensional axial forces $N^{*}$ in the columns with wind direction $\theta$. The general behaviour of $N_{\max }^{*}$ and $N_{\text {min }}^{*}$ with $\theta$ is similar to that of the mean $C_{\mathrm{L}}$ and $C_{\mathrm{My}}$ values shown in Figure 10. In the case of larger $f / B$ ratios, such as $f / B \geq 0.3$, the values of $\left|N_{\text {max }}^{*}\right|$ and $\left|N_{\text {min }}^{*}\right|$ at $\theta=30-45^{\circ}$ are larger than those at $\theta=0^{\circ}$. The difference becomes larger as the $f / B$ ratio increases. When $f / B \geq 0.4$, the values of $N_{\text {max }}^{*}$ and $N_{\text {min }}^{*}$ at $\theta=30-45^{\circ}$ are more than twice those for $\theta=0^{\circ}$.

The net wind-pressure coefficients for designing the cylindrical free-standing canopy roofs are usually determined on the basis of the results for $\theta=0^{\circ}$. The results shown in Figures 10 and 12 clearly indicate that such a procedure is not appropriate for cylindrical free-standing canopy roofs with larger $f / B$ ratios. A diagonal wind direction should be taken into account for discussing the design wind loads.

\section{Discussion of design wind-force coefficients}

\subsection{Basic concept}

In accordance with the abovementioned results, we consider two wind direction ranges, i.e., $\theta=0-15^{\circ}$ and $20-70^{\circ}$ (referred to as 'WD0' and 'WD45', respectively), when discussing the design wind loads. The representative wind direction is $0^{\circ}$ for $\mathrm{WD} 0$ and $45^{\circ}$ for WD45. In the specification of net wind-pressure coefficients for planar free roofs (e.g., Architectural Institute of Japan [1]), the roof is divided into two zones (the windward and leeward halves) and the constant net wind-pressure coefficients are provided for these zones as a function of roof pitch. Such a zoning is not appropriate for cylindrical free-standing canopy roofs, judging from the distribution of net wind-pressure coefficients in the arc direction (see Figure 8, for example). In the present paper, the roof is therefore divided into three zones, $R_{1}, R_{2}$ and $R_{3}$, as shown in Figure 13, and the constant values of net wind-pressure coefficients, $C_{\mathrm{NW}} C_{\mathrm{NC}}$ and $C_{\mathrm{NL}}$, are provided for these zones. Such a zoning is similar to that for enclosed buildings with cylindrical roofs in the AIJ Recommendations for Loads on Buildings (2015) [1]. This model of net wind-pressure coefficients seems reasonable for WD0 because the contour lines of net wind-pressure coefficients are almost perpendicular to the wind direction (see Natalini et al. [7]). By contrast, for WD45, the distribution of the net wind-pressure coefficient seems different from such a simple model. However, according to Figure 11, the distribution of net wind-pressure coefficients along line $\mathrm{C}$ can be used for evaluating the overall wind forces on the roof, assuming that the distribution in the arc direction does not change in the $y$-direction. Therefore, this model can also be applied to the WD45 case with some modification. 
Assuming that the $C_{\mathrm{f}}$ distribution in the arc direction does not change in the $y$ direction, the lift $L$ and the aerodynamic moment $M_{\mathrm{y}}$ about the $y$ axis may be given by the following equations:

$$
\begin{aligned}
& L=\int_{-\varphi_{0}}^{+\varphi_{0}}(-p(\varphi) \cdot \cos \varphi) \cdot W R d \varphi=-q_{\mathrm{H}} W R \int_{-\varphi_{0}}^{+\varphi_{0}} C_{\mathrm{f}}(\varphi) \cdot \cos \varphi d \varphi \\
& M_{y}=\int_{-\varphi_{0}}^{+\varphi_{0}} p(\varphi) \cdot W R d \varphi \cdot R \sin \varphi==q H W R^{2} \int_{-\varphi_{0}}^{+\varphi_{0}} C_{\mathrm{f}}(\varphi) \cdot \sin \varphi d \varphi
\end{aligned}
$$

The definition of the symbols used in these equations is presented in Figure 13. By putting the $C_{\mathrm{f}}$ values in zones $\mathrm{R}_{1}, \mathrm{R}_{2}$ and $\mathrm{R}_{3}$ as $C_{\mathrm{NW}^{\prime}} C_{\mathrm{NC}}$ and $C_{\mathrm{NL}}$ (constant values), respectively, and using Eqs. (1) and (2), we obtain the following equations:

$$
\begin{gathered}
C_{\mathrm{L}}=\frac{R}{W}\left\{\left(C_{\mathrm{NW}}+C_{\mathrm{NL}}\right)\left(\sin \varphi_{0}-\sin \varphi_{1}\right)+2 C_{\mathrm{NC}} \sin \varphi_{1}\right\} \\
C_{M y}=\frac{R}{f}\left\{\left(C_{N L}-C_{N W}\right)\left(\cos \varphi_{0}-\cos \varphi_{1}\right\}\right.
\end{gathered}
$$

Two load cases named 'A' and ' $\mathrm{B}$ ', providing the maximum tension and compression in the columns, are considered for each wind direction range. Two sets of net wind-pressure coefficients, $C_{\mathrm{NW}^{\prime}} C_{\mathrm{NC}}$ and $C_{\mathrm{NL}}$, are specified so that they provide the maximum tension and compression in the columns, which can be obtained from the time history of $C_{\mathrm{L}}, C_{\mathrm{Mx}}$ and $C_{\mathrm{My}}$.

It should be mentioned that $C_{\mathrm{NW}} C_{\mathrm{NC}}$ and $C_{\mathrm{NL}}$ include the dynamic load effect of turbulent wind. In codes and standards, the wind loads are usually presented by equivalent static loads and the dynamic load effect is taken into account by the gust effect factor. In this framework, the net wind-pressure coefficients $C_{\mathrm{NW}^{\prime}}^{*} C_{\mathrm{NC}}^{*}$ and $C_{\mathrm{NL}}^{*}$ for designing the main wind-force resisting systems may be provided by the following equations:

$$
C_{\mathrm{NW}}^{*}=\frac{\gamma \cdot C_{\mathrm{NW} 0}}{G_{\mathrm{f}}}, C_{\mathrm{NC}}^{*}=\frac{\gamma \cdot C_{\mathrm{NC} 0}}{G_{\mathrm{f}}}, C_{\mathrm{NL}}^{*}=\frac{\gamma \cdot C_{\mathrm{NLO}}}{G_{\mathrm{f}}}
$$

where $C_{\mathrm{NW} 0}, C_{\mathrm{NCO}}$ and $C_{\mathrm{NL} 0}$ are the 'basic values' of $C_{\mathrm{NW}} C_{\mathrm{NC}}$ and $C_{\mathrm{NL}}$, which provide the maximum tension or compression in the columns when $\theta=0^{\circ}$ or $45^{\circ} \cdot \gamma$ represents the correction factor for evaluating the effect of wind direction on the axial forces in the columns, which is defined by the ratio of the peak axial force within the wind direction range (WD0 or WD45) to that computed from the $C_{\mathrm{NW} 0^{\prime}} C_{\mathrm{NC} 0}$ and $C_{\mathrm{NL} 0}$ values for $\theta=0^{\circ}$ or $45^{\circ}$. $G_{\mathrm{f}}$ represents the gust effect factor, which is determined on the basis of the load effect, i.e., the ratio between the maximum peak and the mean values of axial forces in the columns.

\subsection{Basic values of wind-force coefficients}

In the case of planar free roofs, the basic values of net wind-pressure coefficients on the windward and leeward halves are determined on the basis of the combinations of $C_{\mathrm{L}}$ and $C_{\mathrm{My}}$ 
which provide the maximum tension and compression in the columns. By contrast, in the case of cylindrical free-standing canopy roofs, the roof is divided into three zones, as shown in Figure 13. In order to determine the values of $C_{\mathrm{NWO}}, C_{\mathrm{NC} 0}$ and $C_{\mathrm{NL} 0^{\prime}}$ we need three conditions, two of which are given by Eqs. (5) and (6). We require one more condition; thus, we focus on the distribution of net wind-pressure coefficient $C_{\mathrm{f}}$ along the centreline for obtaining the additional condition.

Zone $\mathrm{R}_{2}$ is the widest in area of the three zones and the net wind-pressure coefficient in this zone affects the axial forces in the columns most significantly. Figure 14 shows the maximum, mean and minimum values of the spatially-averaged net wind-pressure coefficient for Zone $\mathrm{R}_{2}$ obtained from the $C_{\mathrm{f}}$ distribution along the centreline when $\theta=0^{\circ}$ or $45^{\circ}$. The minimum (negative) and the maximum (positive) values may be related to the maximum tension and compression induced in the columns. Therefore, these values are used as the basic values $C_{\mathrm{NC} 0}$, for WD0 and WD45.

Using Eqs. (5) and (6), we can obtain the values of $C_{\mathrm{NW0}}$ and $C_{\mathrm{NLO}}$ based on the combination of $C_{\mathrm{L}}$ and $C_{\mathrm{My}}$ together with the abovementioned $C_{\mathrm{NC} 0}$ value, which provide the maximum tension (load case A) and the maximum compression (load case B) in the columns. Figure 15 shows sample results on the phase plane representation (trajectory) of the $C_{\mathrm{My}}-C_{\mathrm{L}}$ relation for $f / B=0.1$ and 0.3 when $\theta=30^{\circ}$. The correlation between $C_{\mathrm{My}}$ and $C_{\mathrm{L}}$ is positive when $f / B=0.1$, and negative when $f / B=0.3$. In any case, the envelope of the $C_{\mathrm{My}}-C_{\mathrm{L}}$ trajectory can be approximated by a hexagon defined by the maximum, mean and minimum values of $C_{\mathrm{My}}$ and $C_{\mathrm{L}}$, as illustrated in Figure 16. Two apexes of the hexagon provide the combinations of $C_{\mathrm{My}}$ and $C_{\mathrm{L}}$ for load cases $\mathrm{A}$ and $\mathrm{B}$. The axial forces induced in the columns are computed for the six combinations of $C_{\mathrm{L}}$ and $C_{\mathrm{My}}$ at the six apexes and two critical conditions are then detected.

\subsection{Correction factor for wind-direction effect}

The maximum tension or compression may occur at a wind direction other than $0^{\circ}$ or $45^{\circ}$, as Figure 12 indicates. The correction factor $\gamma$ is introduced to compensate this feature. This is defined by the ratio of the practical maximum or minimum axial force, which can be obtained from a time history analysis, to the predicted values from the basic values of wind-force coefficients, $C_{\mathrm{NWO}}, C_{\mathrm{NC} 0}$ and $C_{\mathrm{NLO}}$. The calculated results of $\gamma$, represented by $\gamma_{0}$ and $\gamma_{45}$, are shown in Figure 17. In some cases, the value of $\gamma$ is less than 1.0, which indicates that the values of $C_{\mathrm{NWO}}, C_{\mathrm{NCO}}$ and $C_{\mathrm{NL} 0}$ estimated in the previous section are so conservative that they provide larger axial forces than the practical peak values. For evaluating the design wind-force coefficients, the value of $\gamma$ is replaced by 1.0 when $\gamma<1.0$.

\subsection{Gust effect factor}

Figure 18 shows the gust effect factor, defined by the ratio of the maximum or the minimum to the mean axial force induced in the columns, plotted as a function of the mean reduced axial force $N_{\text {mean }}^{*}$ for all $f / B$ ratios and wind directions. When the value of $\left|N_{\text {mean }}^{*}\right|$ is small, $G_{\mathrm{f}}$ exhibits a large value. However, with an increase in $\left|N_{\text {mean }}^{*}\right|$, the values of $G f$ 
collapse into a narrow range of around $G_{\mathrm{f}}=1.8$. This value of $G_{\mathrm{f}}$ corresponds to a peak factor of $g_{\mathrm{f}} \approx 2.1$, based on the quasi-steady assumption (i.e., $\left.G_{\mathrm{f}} \approx\left(1+g_{\mathrm{v}} I_{\text {uH }}\right)^{2} \approx(1+2.1 \times 0.16)^{2}=1.8\right)$. Therefore, $G_{\mathrm{f}}=1.8$ is used for evaluating the design wind-force coefficients in the present paper. In practical applications, the value of $G_{\mathrm{f}}$ specified in building codes and standards for each terrain category can be used for evaluating the design wind loads. The value of $g_{\mathrm{v}}$ mentioned above is somewhat smaller than those used in conventional building design. The reason for this is not clear at present, but it may be related to the turbulence scale of the approach flow. The longitudinal turbulence scale of wind tunnel flow is of the same order of the model size. Therefore, the dynamic load effect may be relatively small compared with the practical ones.

\subsection{Net wind-pressure coefficients for designing the main wind-force resisting systems}

The net wind-pressure coefficients obtained from the abovementioned procedure are summarised in Table 1. It is found that the values of net wind pressure for WD45 are rather large in magnitude compared with those for WD0, particularly for larger $f / B$ ratios. This is due to the flow separation from the top surface of the roof, which generates large levels of suction in the leeward region.

\section{Concluding remarks}

The net wind-pressure coefficients for designing the main wind-force resisting systems of cylindrical free-standing canopy roofs have been investigated based on wind tunnel experiments on the wind-pressure distributions along two representative arc lines as well as on the aerodynamic forces and moments acting on the whole roof. The wind tunnel models were made using a 3D printer, which made the roof thickness as thin as $1 \mathrm{~mm}$ or $2 \mathrm{~mm}$.

First, a discussion was presented of the effect of the Reynolds number on the wind-pressure distribution on the top surface by changing the wind speed $U_{\mathrm{H}}$ at the mean roof height $H$ over a wide range. The Reynolds number $R e$ is defined in terms of $U_{\mathrm{H}}$ and twice the radius of curvature of the cylindrical roof. When $R e$ is larger than approximately $1.0 \times 10^{5}$, the wind-pressure distribution is minutely affected by $R e$. The wind-pressure distribution reasonably represents the full-scale practical situation.

The effects of rise-to-span ratio $f / B$ and wind direction $\theta$ on the wind-pressure coefficients acting on the roof were then investigated. It was found that the overall wind forces can be evaluated by the local distribution of net wind-pressure coefficients along the centreline. The distribution of the net wind-pressure coefficient along the centreline significantly changed with $\theta$.

Finally, the net wind-pressure coefficients, $C^{*}{ }_{\mathrm{NW}}{ }^{\prime} C^{*}{ }_{\mathrm{NC}}$ and $\mathrm{C}_{\mathrm{NL}}^{*}$, for designing the main wind-force resisting systems were proposed for two wind direction ranges: $\theta=0-15^{\circ}$ (WD0) and $\theta=20-70^{\circ}$ (WD45). The roof was divided into three zones (windward, central and leeward) and the wind-force coefficients for these zones were provided as a function of $f / B$. 
For discussing the design wind loads, focus was on the axial forces induced in the columns as the most important load effect, assuming that the roof is rigid and supported by four corner columns. Two load cases providing the maximum tension and compression in the columns were considered; two sets of $C^{*}{ }_{\mathrm{NW}}{ }^{\prime} C^{*}{ }_{\mathrm{NC}}$ and $C^{*}{ }_{\mathrm{NL}}$ were provided as a function of $f / B$ for both WD0 and WD45. For evaluating the design wind loads, the gust effect factor approach was employed.

The present study was financially supported by the Nohmura Foundation for Membrane Structure's Technology (2015).

\section{References}

[1] Architectural Institute of Japan, Recommendations of Loads on Buildings, 2015 (in Japanese).

[2] Ginger J.D., Letchford C.W., Wind loads on planar canopy roofs, Part 2 Fluctuating pressure distributions and correlations, Journal of Wind Engineering and Industrial Aerodynamics, Vol. 51, 1994, 353-370.

[3] Gumley S.J., A parametric study of extreme pressures for the static design of canopy structures, Journal of Wind Engineering and Industrial Aerodynamics, Vol. 16, 1984, 43-56.

[4] Letchford C.W., Ginger J.D., Wind loads on planar canopy roofs, Part 1 Mean pressure distributions, Journal of Wind Engineering and Industrial Aerodynamics, Vol. 45, 1992, 25-45.

[5] Macdonald P.A., Kwok K.C.S., Holmes J.D., Wind loads on circular storage bins, silos and tanks: I. Point pressure measurements on isolated structures, Journal of Wind Engineering and Industrial Aerodynamics, Vol. 31, 1988, 165-188.

[6] Natalini B., Marighetti J.O., Natalini M.B., Wind tunnel modeling of mean pressures on planar canopy roof, Journal of Wind Engineering and Industrial Aerodynamics, Vol. 90, 2002, 427-439.

[7] Natalini M.B., Morel C., Natalini B., Mean loads on vaulted canopy roofs, Journal of Wind Engineering and Industrial Aerodynamics, Vol. 119, 2013, 102-113.

[8] Takeda F., Yoshino T., Uematsu Y., Design wind force coefficients for hyperbolic paraboloid free roofs, Journal of Physical Science and Application, Vol. 4(1), 2014, 1-19.

[9] Ueda H., Hagura H., Oda H., Characteristics of stress generated by wind pressures and wind loads acting on stiff two-hinged arches supporting a barrel roof, Journal of Structural and Construction Engineering, Architectural Institute of Japan, Vol. 496, 1997, 29-35 (in Japanese).

[10] Uematsu Y., Iizumi E., Stathopoulos T., Wind loads on free-standing canopy roofs: Part 1 local wind pressures, Journal of Wind Engineering and Industrial Aerodynamics, Vol. 96, 2008, 1015-1028.

[11] Uematsu Y., Iizumi E., Stathopoulos T., Wind loads on free-standing canopy roofs: Part 2 overall wind forces, Journal of Wind Engineering and Industrial Aerodynamics, Vol. 96, 2008, 1029-1042. 
[12] Uematsu Y., Sakurai H., Miyamoto Y., Gavanski E., Wind force coefficients for designing porous canopy roofs, Journal of Civil Engineering and Architecture, Vol. 7(9), 2013, $1047-1055$.

[13] Uematsu Y., Miyamoto Y., Gavanski E., Wind loading on a hyperbolic paraboloid free roof, Journal of Civil Engineering and Architecture, Vol. 8(10), 2014, 1-19.

[14] Uematsu Y., Miyamoto Y., Gavanski E., Effects of porosity on the Wind loads on a hyperbolic paraboloid canopy roof. Journal of Civil Engineering and Architecture, Vol. $9(6), 2015,715-726$.

[15] Uematsu Y., Iizumi E., Stathopoulos, T., Wind loads on free-standing canopy roofs Part 3 Validity and application of the proposed wind force coefficients, Journal of Wind Engineering, JAWE, Vol. 31(4), 2006, 115-122 (in Japanese).

[16] Uematsu Y., Iizumi E., Stathopoulos, T., Wind force coefficients for the main wind force resisting system of a free-standing canopy roof of cantilever type, Proceedings of the $19^{\text {th }}$ National Symposium on Wind Engineering, 2006, 343-348 (in Japanese). 


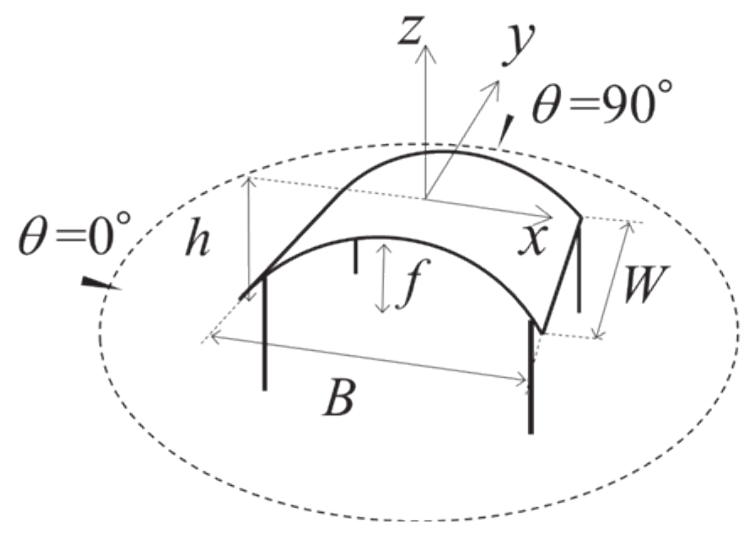

Fig. 1. Model building and coordinate system

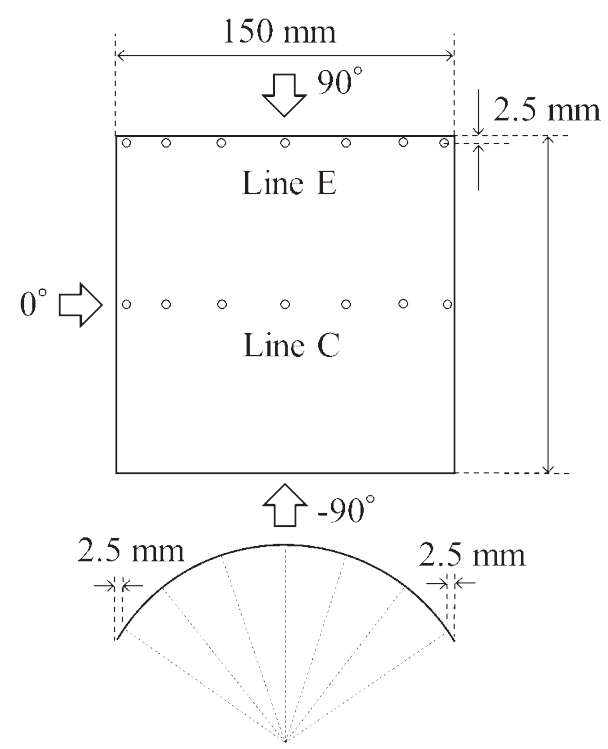

(a) Layout of pressure taps
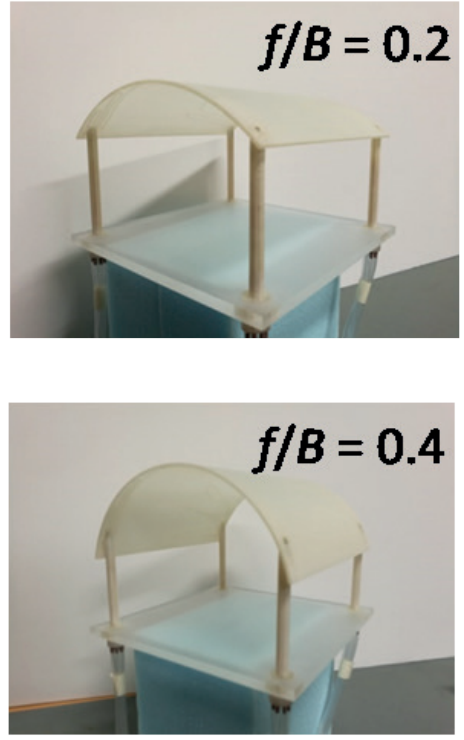

(b) Pictures

Fig. 2. Wind tunnel models for pressure measurements 


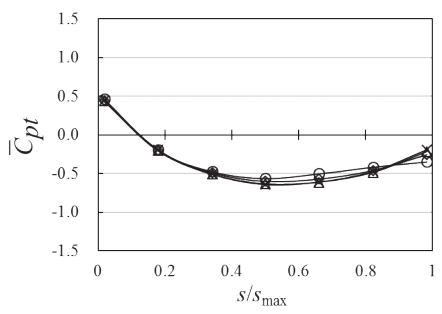

(a) $\bar{C}_{\text {pt }}$

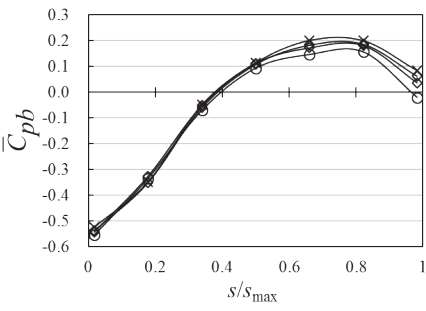

(b) $\bar{C}_{\mathrm{pb}}$

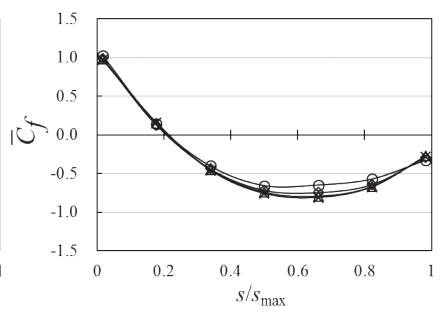

(c) $\bar{C}_{f}$

Fig. 3. Distributions of the mean wind-pressure coefficients and the net wind-pressure coefficients $\left(f / B=0.1, \theta=0^{\circ}\right.$, line $\left.C\right)$

$\times: R e=1.22 \times 10^{5} \sqsubset: R e=1.11 \times 10^{5} \Delta: R e=1.00 \times 10^{5} \bigcirc: R e=0.66 \times 10^{5} \bigcirc: R e=0.33 \times 10^{5}$

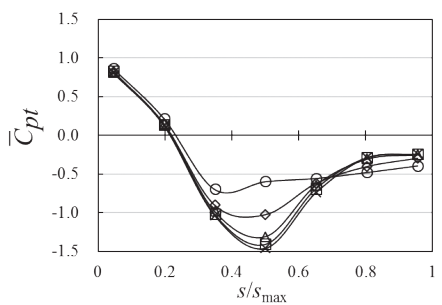

(a) $\bar{C}_{p t}$

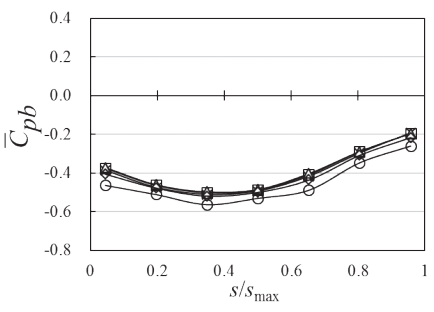

(b) $\bar{C}$

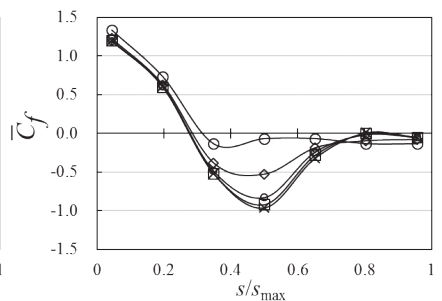

(c) $\bar{C}_{\mathrm{f}}$

Fig. 4. Distributions of the mean wind-pressure coefficients and the net wind-pressure coefficients

$$
\left(f / B=0.4, \theta=0^{\circ} \text {, line } C\right)
$$

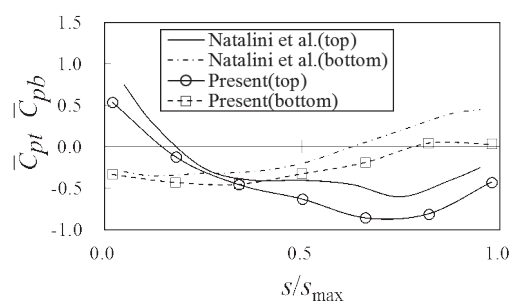

(a) Line $\mathrm{E}$

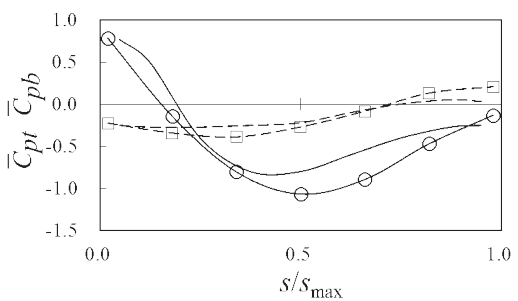

(b) Line C

Fig. 5. Distributions of the mean wind-pressure coefficients along lines $\mathrm{E}$ and $\mathrm{C}$ when $f / B=0.2$ and $\theta=0^{\circ}$ : comparison between the present and previous experiments 


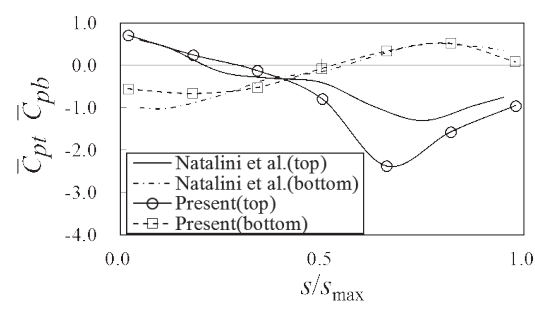

(a) Line $\mathrm{E}$

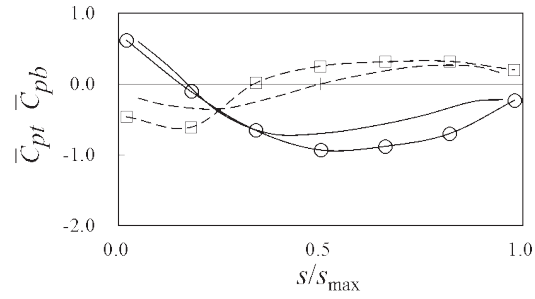

(b) Line C

Fig. 6. Distributions of the mean wind-pressure coefficients along lines $\mathrm{E}$ and $\mathrm{C}$ when $f / B=0.2$ and $\theta=30^{\circ}$ : comparison between the present and previous experiments

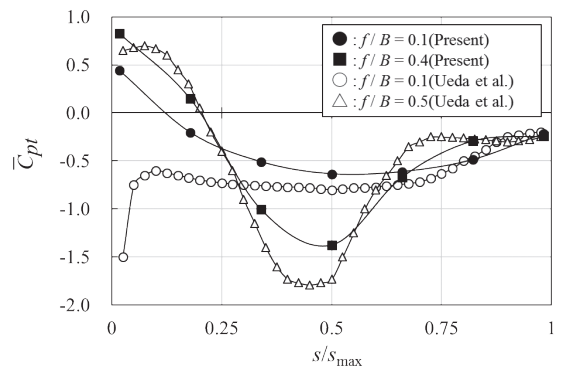

Fig. 7. Mean wind-pressure coefficients on the top surface: a comparison with those on enclosed structures

$\bigcirc: f / B=0.1 \diamond: f / B=0.2 \triangle: f / B=0.3 \square: f / B=0.4$

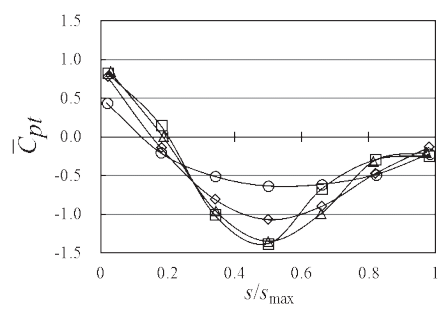

(a) $\bar{C}_{p t}$

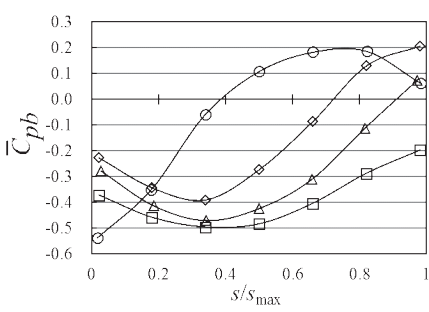

(b) $\bar{C}_{\mathrm{pb}}$

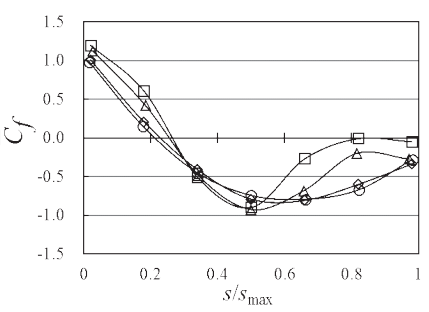

(c) $\bar{C}_{\mathrm{f}}$

Fig. 8. Distributions of the mean wind-pressure coefficients and the net wind-pressure coefficients along line $C\left(\theta=0^{\circ}\right)$ 
$\bigcirc: f / B=0.1 \diamond: f / B=0.2 \triangle: f / B=0.3 \square: f / B=0.4$

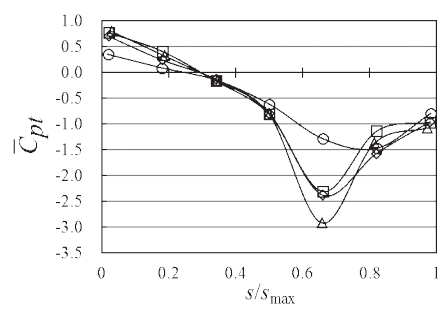

(a) $\bar{C}_{\text {pt }}$

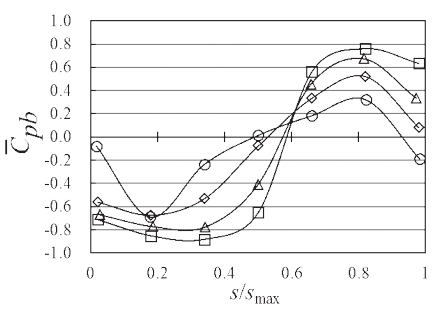

(b) $\bar{C}_{\mathrm{pb}}$

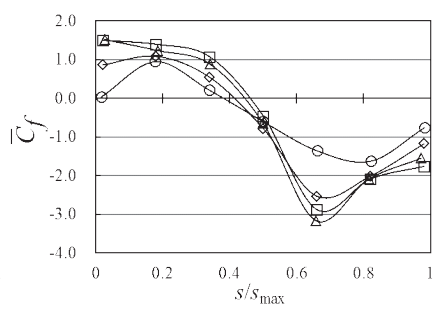

(c) $\bar{C}_{\mathrm{f}}$

Fig. 9. Distributions of the mean wind-pressure coefficients and the net wind-pressure coefficients along line $\mathrm{E}\left(\theta=30^{\circ}\right)$

: $f / B=0.1 \diamond: f / B=0.2 \Delta: f / B=0.3 \mathbf{\square}: f / B=0.4 \times: f / B=0.5$

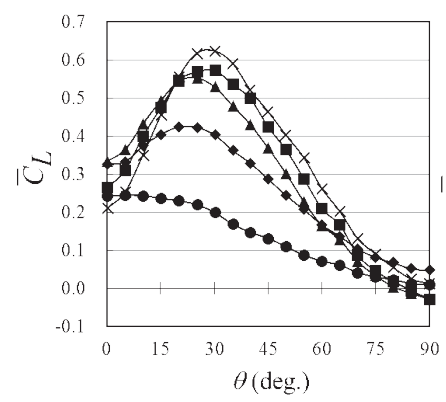

(a) $\mathrm{C}_{\mathrm{L}}$

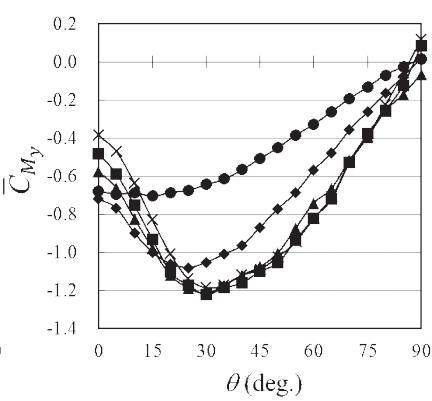

(b) $\bar{C}_{\text {My }}$

Fig. 10. Variation of the mean $C_{\mathrm{L}}$ and $C_{\mathrm{My}}$ values with $\theta$

風力測定 $[\bigcirc: f / B=0.1 \diamond: f / B=0.2 \triangle: f / B=0.3 \square: f / B=0.4]$ 風圧測定 $[\bigcirc: f / B=0.1 \vee: f / B=0.2 \Delta: f / B=0.3 \square: f / B=0.4]$

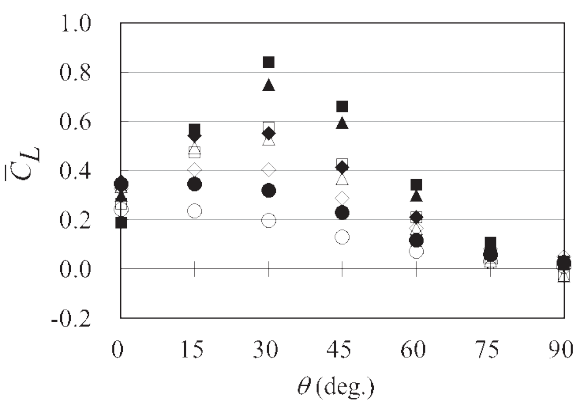

(a) $\mathrm{C}_{\mathrm{L}}$

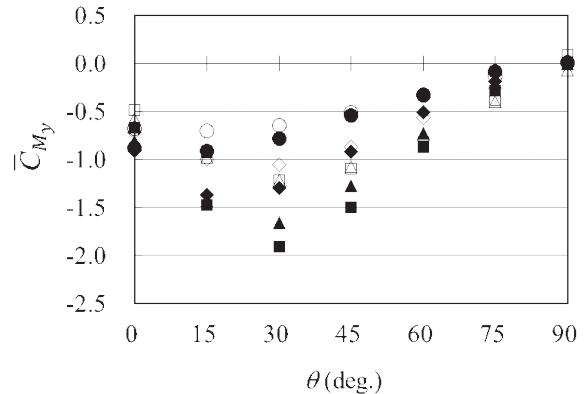

(b) $\bar{C}_{\text {My }}$

Fig. 11. Comparison between the local and overall values for the mean $C_{\mathrm{L}}$ and $C_{\mathrm{My}}$ values 
$f / B=0.1$

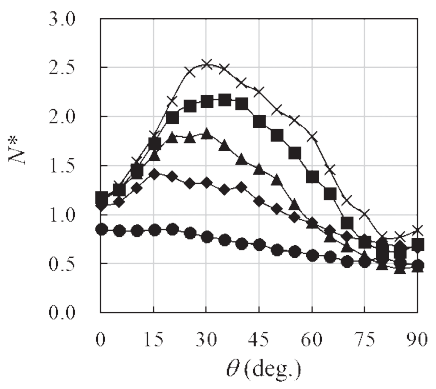

(a) $N_{\text {max }}^{*}$ (tension)

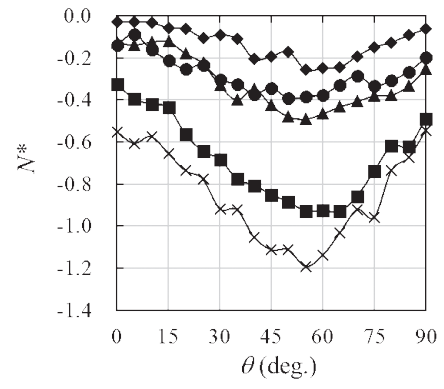

(b) $N_{\min }^{*}$ (compression)

Fig. 12. Variation of $N_{\text {max }}^{*}$ and $N_{\text {min }}^{*}$ with wind direction $\theta$

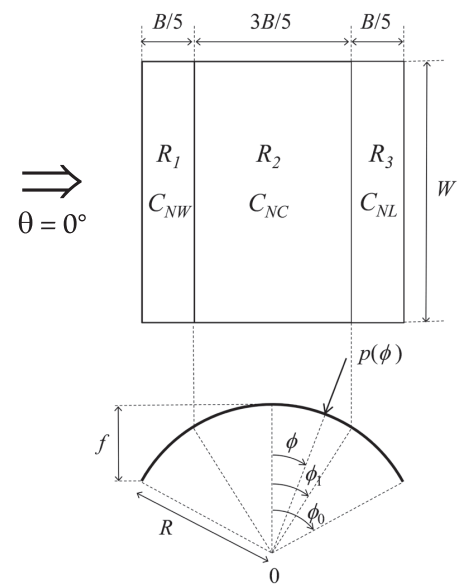

Fig. 13. Zoning of the roof and wind-force coefficients

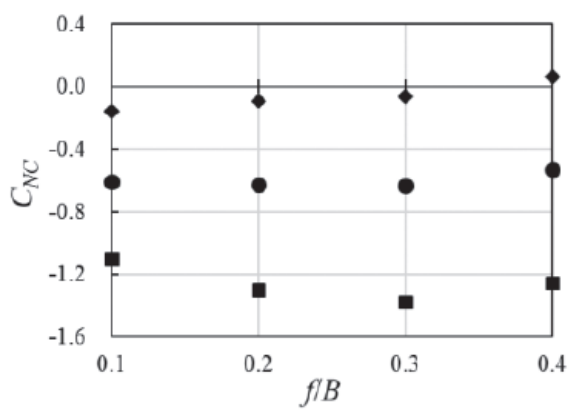

(a) $\theta=0^{\circ}$

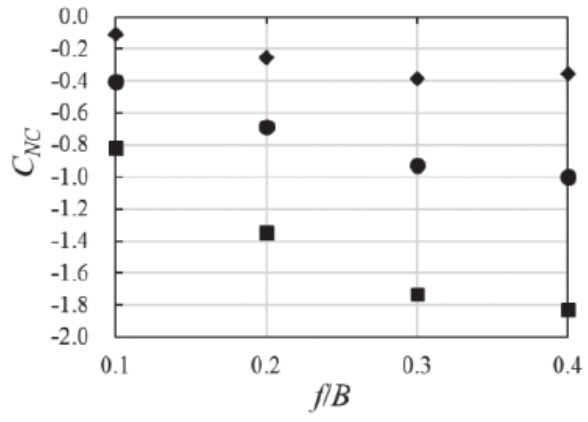

(b) $\theta=45^{\circ}$

Fig. 14. Spatially-averaged wind force coefficient for Zone $\mathrm{R}_{2}$ 


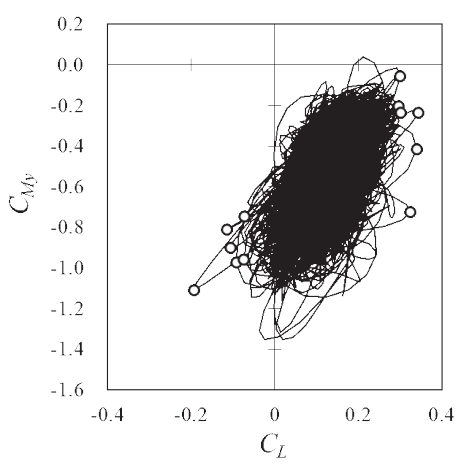

(a) $f / B=0.1$

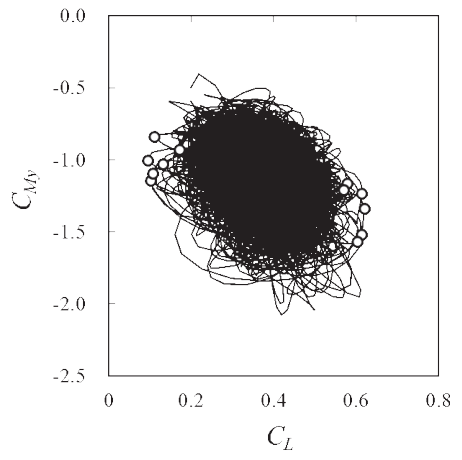

(b) $f / B=0.3$

Fig. 15. $C_{\mathrm{My}}-C_{\mathrm{L}}$ trajectory $\left(\theta=30^{\circ}\right)$

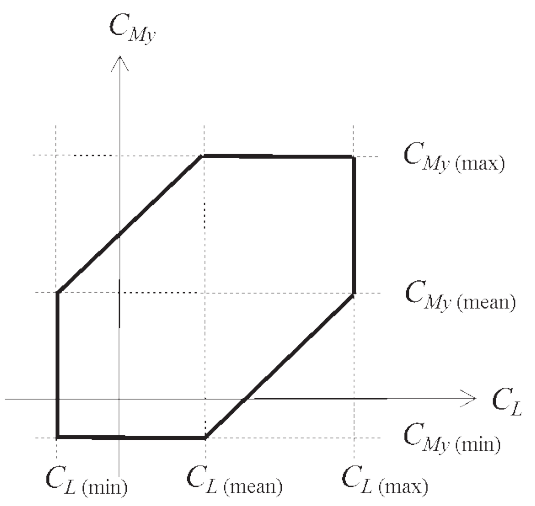

(a) Positive correlation

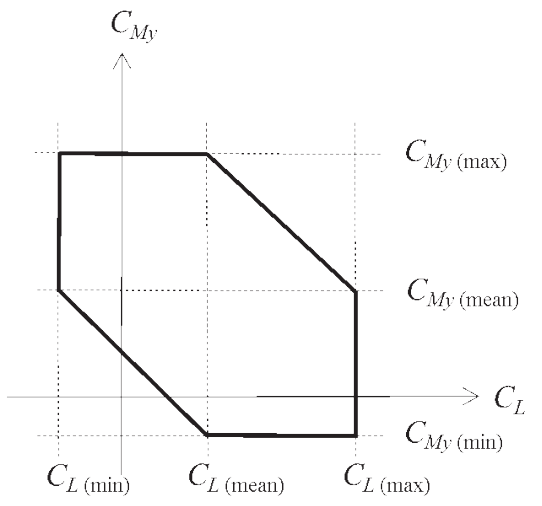

(b) Negative correlation

Fig. 16. Model of the envelope of the $C_{\mathrm{My}}-C_{\mathrm{L}}$ trajectory

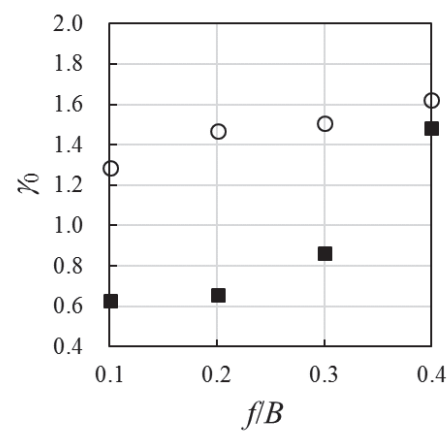

(a) WD0

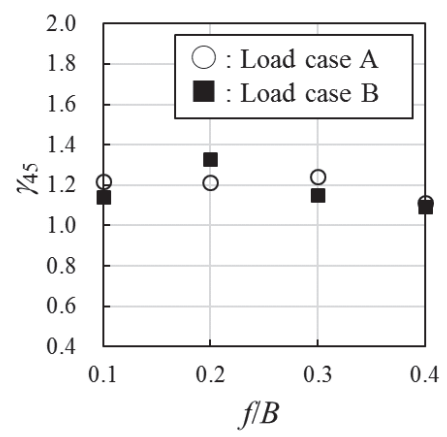

(b) WD45

Fig. 17. Correction factor for the wind-direction effect on the maximum and minimum column axial forces 


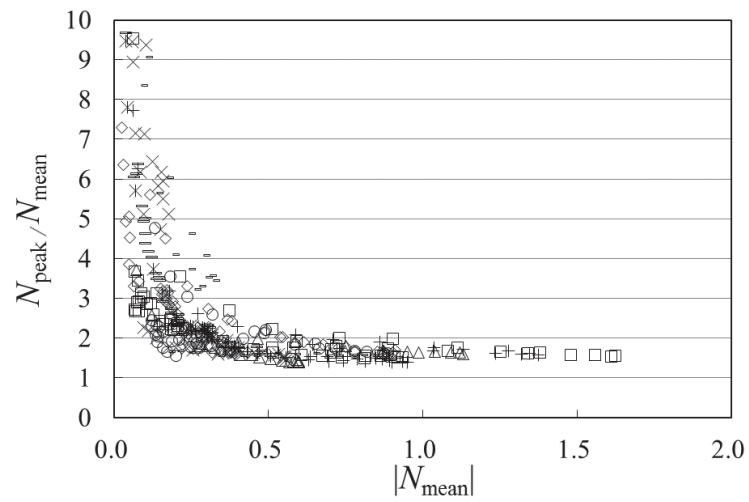

Fig. 18. Gust effect factor based on the load effect

Table 1. Design wind-force coefficients

(a) Wind direction WD0

\begin{tabular}{|c|c|c|c|c|c|c|c|}
\hline \multicolumn{2}{|c|}{} & \multicolumn{2}{c|}{$C_{\mathrm{NW}}^{*}$} & \multicolumn{2}{c|}{$C_{\mathrm{NC}}^{*}$} & \multicolumn{2}{c|}{$C_{\mathrm{NL}}^{*}$} \\
\hline \multicolumn{2}{|c|}{ Load case } & $\mathrm{A}$ & $\mathrm{B}$ & $\mathrm{A}$ & $\mathrm{B}$ & $\mathrm{A}$ & $\mathrm{B}$ \\
\hline \multirow{3}{*}{$f / B$} & 0.1 & 1.3 & 0.6 & -0.5 & 0.0 & -0.5 & -0.4 \\
\cline { 2 - 8 } & 0.2 & 0.8 & 0.1 & -0.6 & 0.0 & -1.0 & -0.3 \\
\cline { 2 - 8 } & 0.3 & 0.8 & 0.2 & -0.7 & 0.0 & -1.0 & -0.4 \\
\cline { 2 - 8 } & 0.4 & 0.9 & 0.3 & -0.8 & 0.0 & -0.7 & -0.7 \\
\hline
\end{tabular}

(b) Wind direction WD45

\begin{tabular}{|c|c|c|c|c|c|c|c|}
\hline \multicolumn{2}{|c|}{} & \multicolumn{2}{|c|}{$C_{\mathrm{NW}}^{*}$} & \multicolumn{2}{c|}{$C_{\mathrm{NC}}^{*}$} & \multicolumn{2}{c|}{$C_{\mathrm{NL}}^{*}$} \\
\hline \multirow{2}{*}{$f / B$} & $\mathrm{~A}$ & $\mathrm{~B}$ & $\mathrm{~A}$ & $\mathrm{~B}$ & $\mathrm{~A}$ & $\mathrm{~B}$ \\
\hline \multirow{3}{*}{$f / B$} & 0.1 & 0.2 & 0.7 & -0.6 & 0.0 & -0.4 & -0.4 \\
\cline { 2 - 8 } & 0.2 & 0.8 & 0.6 & -0.7 & -0.1 & -1.0 & -1.3 \\
\cline { 2 - 8 } & 0.3 & 0.8 & 0.8 & -0.8 & -0.3 & -1.1 & -2.3 \\
\cline { 2 - 8 } & 0.4 & 0.7 & 0.8 & -0.8 & -0.4 & -1.3 & -2.7 \\
\hline
\end{tabular}

